\title{
Subjective Visual Vertical Perception in Peripheral Vestibular Diseases
}

\author{
Mario Faralli ${ }^{1}$, Ruggero Lapenna ${ }^{1}$, Luca D'Ascanio ${ }^{2 *}$, Laura Cipriani ${ }^{1}$ and Giampietro Ricci ${ }^{1}$ \\ ${ }^{1}$ Department of Surgical and Biomedical Sciences, Section of Otolaryngology-Head and Neck Surgery, University of Perugia, Perugia, Italy \\ ${ }^{2}$ Department of Otolaryngology - Head \& Neck Surgery, "Carlo Poma" Civil Hospital, Mantova, Italy
}

Submission: April 22, 2017; Published: May 04, 2017

*Corresponding author: Luca D’Ascanio, Department of Otolaryngology - Head \& Neck Surgery, Carlo Poma, Civil Hospital, Strada Lago Paiolo 10 , 46100 Mantova, Italy, Tel: +39-3283186967; Fax: +39-075-5783574; Email: l.dascanio@gmail.com

\begin{abstract}
Objective: to examine the utility of subjective visual vertical (SVV) measurement in peripheral vestibular diseases.

Materials and Methods: 91 patients were evaluated. Among them, 40 subjects were diagnosed with an acute unilateral vestibular loss (AUVL), 30 patients with a benign paroxysmal positional vertigo (BPPV) and 21 with Ménière's disease (MD). In AUVL, we carried out a baseline (BT) and a provocative test (PT) with the interposition of a soft support between patients' feet and the ground. In BPPV, the SVV was determined at the time of diagnosis, after the first therapeutic maneuver and 7 days later. In MD, SVV assessment was carried out during the attack and 7 days later with comparative assessment of concurrent spontaneous nystagmus (SN).
\end{abstract}

Results: AUVL patients showing a better use of proprioception on SVV $\left(4.83 \pm 0.94^{\circ} \mathrm{BT}, 6.41 \pm 0.98^{\circ} \mathrm{PT}\right.$; $\left.\mathrm{p}<0.001\right)$ were able to correct SVV deviation more quickly than others ( $62 \%$ vs $7 \%$; $p<0.001$ at 30 days). A significant change in SVV was recorded in BPPV after repositioning maneuvers $(0.75 \pm 0.49$ vs $0.054 \pm 0.79 ; \mathrm{p}<0.001)$. During an acute attack of initial MD, SVV can show an opposite functional status with respect to the SN significantly more frequently than in non initial MD ( $57 \%$ vs. $0 \%$; $p<0.05)$.

Conclusion: In AUVL, SVV can be useful to follow-up the long-term recovery. In BPPV, SVV determination can predict the effectiveness of repositioning maneuvers. Finally, SVV assessment can help differentiate MD initial attacks from non-initial MD attacks and AVUL.

Keywords: Subjective visual vertical; Spontaneous nystagmus; Vestibular neuritis; Paroxysmal positional vertigo; Ménière’s disease

Abbreviations: SVV: Subjective Visual Vertical; SN: Spontaneous Nystagmus; oVEMPs: ocular Vestibular Evoked Myogenic Potentials; AUVL: Acute Unilateral Vestibular Loss; MD: Ménière's disease; BPPV: Benign Paroxysmal Positional Vertigo; OTR: Ocular Tilt Reaction; PSC: Posterior Semicircular Canal

\section{Introduction}

Vestibular clinical examinations in dizzy patients have been traditionally based on the assessment of the signs of semicircular canals function, such as spontaneous nystagmus (SN). However, the recent development of new tests allows a more accurate assessment of otolithic functions. In particular, the utility of subjective visual vertical (SVV) measurement and electrophysiological technique of ocular vestibular evoked myogenic potentials (oVEMPs) in the assessment of utricular function has been reported [1]. While oVEMPs assess macula response in "dynamic" conditions (during vibration-induced activation), SVV assesses vestibular function in "static" conditions (related to the tonic activation of otolithic signals).

The clinical expression of otolithic damage is represented by the so-called «Ocular Tilt Reaction» (OTR), characterized by head tilt, vertical ocular misalignment (skew deviation), and binocular cyclotorsion (ocular counter roll) [2,3]. The ocular counter roll, in particular, is considered to have a predominantly utricular origin [4]. Ocular fundus examination, showing the mismatch between the optic disc and the fovea, is required to objectify binocular cyclotorsion. Its indirect perceptual effects can be evaluated by SVV assessment.

SVV is defined as a person's ability to indicate, in his judgment and under specific experimental conditions, a vertical line: normally, the vertical line indicated by the subject approaches the gravitational vector with good approximation [4]. In case of damage within the peripheral vestibular system or the lower brainstem, the deviation of the SVV is ipsilesional and shows an orientation opposite to SN rapid phase direction $[3,5]$. If the lesion is higher within the central vestibular system, SVV deviation will be ipsilateral to SN rapid phase because 
of the involvement of the interstitial nucleus of Cajal, or the medial longitudinal fasciculus which crosses the brainstem midline [6]. We report a prospective study about SVV features in patients affected by peripheral vestibular diseases. A possible pathophysiological explanation of our findings is reported.

\section{Materials and Methods}

We enrolled 91 consecutive patients suffering from vertigo due to peripheral vestibular diseases between March 2009 and December 2012. The authors assert that all procedures contributing to this work comply with the ethical standards of the relevant national and institutional guidelines on human experimentation and with the Helsinki Declaration of 1975, as revised in 2008. Local ethics committee approved the study and all patients gave their informed consent. The diagnosis was carried out in all subjects after complete audiological and vestibular evaluations, in addition to neurological or neuroradiological investigation in case of diagnostic doubt. Among our patients, 40 subjects suffered from acute unilateral vestibular loss (AUVL); 30 from benign paroxysmal positional vertigo (BPPV) of the posterior semicircular canal (PSC); and 21 subjects from Menière's Disease (MD). Among MD patients, 12 were considered to have "definite" MD and 9 "probable" MD, according to the American Academy of Otolaryngology-Head and Neck Surgery [7]. The whole study sample was composed of 47 females and 44 males with a mean age of $49.2 \pm 7.9$ years.

The assessment of SVV was carried out with the patient standing up in a completely darkened room with the only visible object represented by a handmade rotating dimly lit bar of $30 \times 1 \mathrm{~cm}$ in size, placed at a distance of $1.5 \mathrm{~m}$ from the subject. Subsequently, after providing appropriate instructions, the operator moves the bar rotating around an axis coinciding with the plane passing through the patient's eyes. After placing the bar rotated, the patient is asked to rotate the bar back to the vertical position by using a handle. A graduated scale is used to measure the degrees of bar inclination. Conventionally, inclinations towards the right side are indicated as positive values, those to the left as negative, while $0^{\circ}$ corresponds to the perfect alignment of the bar with the gravitational axis. The test is repeated 6 times, with the bar moved by the operator 3 times to the right and 3 times to the left side. The definite VVS is obtained by calculating the average value of the 6 measurements (VVSO).

\section{AUVL}

Diagnosis of AUVL was carried out in case of unidirectional SN with positive Head Impulse Test (HIT) (ISC Impulse, Otometrics, Taastrup, Denmark) abnormal caloric response (bithermic caloric stimulator, Menfis bioMedica, Bologna, Italy) and normal audiogram (Amplaid A315, Amplifon, Milan, Italy). In these patients, SVV measurements were carried out within 2 days from symptoms onset. First, a baseline test (BT) with the patient in an upright position and in direct contact with the ground was performed. Then, we carried out a provocative test (PT) with the interposition of a soft support between the patient's feet $(40 \times 40$ $\mathrm{cm}$ ) and the ground to reduce proprioceptive plantar input. SVV test was repeated in all patients after 30, 90 and 180 days after identical medical treatment with prednisone (Deltacortene, Bruno Farmaceutici, Rome, Italy) $25 \mathrm{mg}$ bid then gradually tapered.

\section{Benign Paroxysmal Positional Vertigo}

In patients with BPPV the SVV was determined on 3 occasions:

a) at the time of diagnosis, after Dix-Hallpike diagnostic maneuver and before any therapeutic repositioning maneuver;

b) after the first therapeutic Epley repositioning maneuver (before the repetition of the diagnostic maneuver preformed to verify the treatment efficacy);

c) one week after resolution (confirmed by Dix-Hallpike maneuver).

\section{Menière's Disease}

In MD patients SVV assessment was carried out on 2 occasions: during the attack, and 7 days later, after identical medical treatment with prednisone (Deltacortene, Bruno Farmaceutici, Rome, Italy) $25 \mathrm{mg}$ bid then gradually tapered and betahistine (Vertiserc, Abbot, Chicago, U.S.) $24 \mathrm{mg}$ bid for all patients. After one week, control caloric stimulation was carried out to assess lateral semicircular canal functional status.

\section{Control group}

We also assessed SVV in a control group of 20 healthy subjects not affected by vestibular diseases. Among them, SVV was found to be $0.10+0.73^{\circ}$ in BT and $0.9+0.82$ in PT.

\section{Statistical analysis}

SPSS Statistic (IBM, Armonk, New York, U.S.) software was used to perform statistical analysis. The average values of SVV deviation in every group of patients $\left(\mathrm{SVV}_{\text {med }}\right)$ were calculated using SVV0 absolute values for each patient and were indicated as mean \pm SD. Statistical analysis of obtained data was performed by using the Student's t test $\left(\mathrm{p}_{\mathrm{s}}\right)$, Paired t test $\left(\mathrm{p}_{\mathrm{p}}\right)$, Pearson's Chisquare $\left(\mathrm{p}_{\mathrm{c}}\right)$, one-way ANOVA $\left(\mathrm{p}_{\mathrm{A}}\right)$ with post hoc analysis with Tukey's test and Fisher's exact test $(\mathrm{pF})$, where appropriate. Level of significance was set at $\mathrm{p}<0.05$.

\section{Results}

\section{AUVL}

All 40 patients showed an ipsilesional deviation of SVV in the acute phase. $\mathrm{SVV}_{\text {med }}$ in BT $\left(4.86 \pm 0.93^{\circ}\right)$ and PT $\left(5.11 \pm 1.21^{\circ}\right)$ was significantly greater $(\mathrm{pS}<0.05)$ than the respective condition in 
healthy control subjects, with no significant difference between the BT and PT conditions ( $\left.\mathrm{p}_{\mathrm{P}}>0.05\right)$. According to SVV0 values on BT and PT, we divided our patients into 3 groups:

a) Group A: 13 patients, who showed a significant increase of their SVV0 values during the PT compared to BT $\left(\mathrm{p}_{\mathrm{p}}<0.05\right)$.

b) Group B: 8 patients, who showed a significant decrease in their SVV0 values during the PT compared to BT $\left(\mathrm{p}_{\mathrm{P}}<\right.$ $0.05)$.

c) Group C: 19 patients, who showed no significant change in their SVV0 values during the PT compared to BT $\left(\mathrm{p}_{\mathrm{P}}>0.05\right)$.

Table 1: Data about SVVmed in basal conditions (BT) or during the provocative test (PT) in case of acute unilateral vestibular loss (acute phase).

\begin{tabular}{|c|c|c|c|c|c|}
\hline & Group A & Group B & Group C & $\begin{array}{l}\text { Control } \\
\text { group }\end{array}$ & p \\
\hline $\begin{array}{c}\text { SVVmed } \\
\text { BT }\end{array}$ & $\begin{array}{l}4.83 \pm \\
0.94^{\circ} \\
(* * * *)\end{array}$ & $\begin{array}{c}5.19 \pm \\
0.39^{\circ} \\
(* * * *)\end{array}$ & $\begin{array}{l}4.74 \pm \\
1.09^{\circ} \\
(* * *)\end{array}$ & $\begin{array}{c}0.10 \pm \\
0.73^{\circ} \\
(*, * *, * * *)\end{array}$ & $\begin{array}{c}\mathrm{pA}< \\
0.001\end{array}$ \\
\hline $\begin{array}{c}\text { SVVmed } \\
\text { PT }\end{array}$ & $\begin{array}{c}6.41 \pm \\
0.98^{\circ} \\
(* * * *)\end{array}$ & $\begin{array}{c}3.92 \pm \\
0.46 \\
(*, * * * *)\end{array}$ & $\begin{array}{c}4.8 \pm \\
0.92^{\circ} \\
(*, * * * *)\end{array}$ & $\begin{array}{c}0.09 \pm \\
0.82^{\circ} \\
(*, * *, * * *)\end{array}$ & $\begin{array}{c}\mathrm{pA}< \\
0.001\end{array}$ \\
\hline $\mathrm{p}$ & $\begin{array}{c}\mathrm{pP}< \\
0.001\end{array}$ & $\begin{array}{c}\mathrm{pP}< \\
0.001\end{array}$ & $\mathrm{pP}<0.05$ & $\mathrm{pP}>0.05$ & \\
\hline
\end{tabular}

Statistical analysis is reported: $p P=p$ value from paired test, $p A=p$ value from one-way ANOVA, statistical significance at post hoc Tukey's test of pair-wise comparison with group $A\left({ }^{*}\right)$, with group $B\left({ }^{* *}\right)$, group $\left.C{ }^{* * *}\right)$, and control group $\left(^{* * * *}\right)$. SVVmed: average value of Subjective Visual Vertical in the group; BT: baseline test; PT: provocative test

Data about $\mathrm{SVV}_{\text {med }}$ during the acute phase from the 3 groups and relative statistical analysis are shown in (Table 1). After 30 days, SVV0 showed normalization (values between $\pm 2^{\circ}$ ) in 8 patients $(61.5 \%)$ in group A, no subject in group B, and 2 $(10.5 \%)$ in group C. After 90 days, SVV0 showed normalization in 13 patients $(100 \%)$ in group A, $1(12.5 \%)$ in the group B, and $5(26.3 \%)$ in group C. After 180 days, SVV0 showed normal values in all patients from group A, $1(12.5 \%)$ in group B, and $13(68.4 \%)$ in group C. This distribution among groups and controls was statistically significant $\left(\mathrm{p}_{\mathrm{C}}<0.001\right)$. The KaplanMeier survival curve showed this different pattern of SVV return to normal values in the 3 different groups. In particular, group A had the lowest "survival" rate, followed by group $\mathrm{C}$ and then group B (Figure 1).

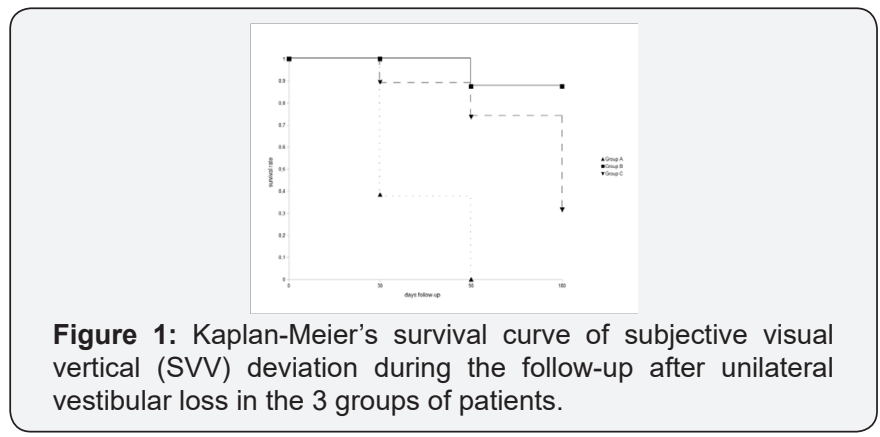

\section{Benign Paroxysmal Positional Vertigo}

18 patients had a right PSC BPPV and 12 a left PSC BPPV. On the $1^{\text {st }}$ test, all patients showed a deviation of SVV ipsilateral to the involved PSC. In patients with right PSC BPPV, SVV ${ }_{\text {med }}$ was $0.88 \pm 0.5^{\circ}$ on the 1 st test, $-0.01 \pm 0.92$ on the ${ }^{2 \text { nd }}$ test, and 0.13 \pm 0.78 on the $3^{\text {rd }}$ test. In patients with left PSC BPPV, SVVmed was $-0.62 \pm 0.47$ on the 1 st test, $0.097 \pm 0.65$ on the $2^{\text {nd }}$ one, and $0.10 \pm 0.76$ on the $3^{\text {rd }}$ test. One-way ANOVA showed a main effect of the moment of the test both on right PSC BPPV patients and left PSC BPPV subjects $\left(\mathrm{p}_{\mathrm{A}}<0.05\right)$. One way ANOVA showed a main effect of the group only during the 1 st test $\left(\mathrm{p}_{\mathrm{A}}<0.05\right)$, but not during the $2^{\text {nd }}$ and $3^{\text {rd }}$ test $(\mathrm{pA}>0.05)$. Figure 2 shows the different error bars of SVVmed with the post-hoc analysis with Tukey's test.

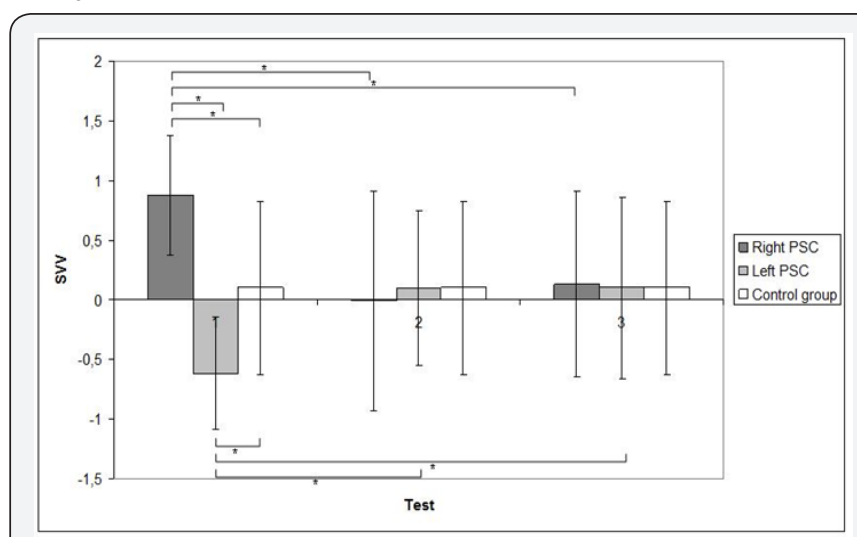

Figure 2: Error bars of subjective visual vertical (SVV) values in benign paroxysmal positional vertigo patients according to different tests and groups; PSC: posterior semicircular canal. Significance $\left(^{*}\right)$ at post analysis with Tukey's test is shown.

After the first therapeutic Epley repositioning maneuver, Dix-Hallpike control showed vertigo resolution in $15 / 18$ (83.3\%) right side BPPV patients, and 8/12 (66.6\%) left side BPPV subjects. Among these 23 patients with vertigo resolution, 16 had an inversion of SVV deviation direction, while the other 7 showed no SVV inversion on the $2^{\text {nd }}$ test. The inversion of SVV was significantly correlated with the success of the repositioning maneuver $\left(\mathrm{p}_{\mathrm{F}}=0.009\right)$.

\section{Menière's Disease}

Attack: Data obtained during the acute attack and statistical analysis is reported in (Table 2). 
Table 2: Clinical data and statistical analysis in patients with Menière's Disease (MD).

\begin{tabular}{|c|c|c|c|c|}
\hline & & $\begin{array}{c}\text { Probable } \\
\text { MD }\end{array}$ & $\begin{array}{c}\text { Definite } \\
\text { MD }\end{array}$ & p value \\
\hline \multirow{3}{*}{$\begin{array}{l}\text { Acute } \\
\text { attack }\end{array}$} & PTA dBHL & $\begin{array}{c}36.11 \pm \\
7.82\end{array}$ & $\begin{array}{c}47.73 \pm \\
12.32\end{array}$ & $\mathrm{p}<0.05$ \\
\hline & SVVmed & $4.36 \pm 1.66^{\circ}$ & $\begin{array}{c}5.22 \pm \\
2.35^{\circ}\end{array}$ & $\mathrm{p}>0.05$ \\
\hline & $\begin{array}{c}\text { Indications } \\
\text { (maculo-canal } \\
\text { dissociation vs } \\
\text { correspondence) }\end{array}$ & $4 / 3$ & $0 / 9$ & $p=0.0192$ \\
\hline \multirow{3}{*}{$\begin{array}{l}1 \text { week } \\
\text { control }\end{array}$} & PTA dBHL & $\begin{array}{c}14.44 \pm \\
3.91^{\circ}\end{array}$ & $\begin{array}{c}27.50 \pm \\
10.77^{\circ}\end{array}$ & $\mathrm{p}<0.01$ \\
\hline & SVVmed & $0.86 \pm 0.44^{\circ}$ & $\begin{array}{c}2.08 \pm \\
1.14^{\circ}\end{array}$ & $\mathrm{p}<0.01$ \\
\hline & $\begin{array}{c}\text { Deficit to } \\
\text { bithermal } \\
\text { stimulation }\end{array}$ & 0 & 5 & $\mathrm{p}<0.05$ \\
\hline
\end{tabular}

MD: Ménière's Disease; PTA dBHL: Pure tone Audiometry decibe Hearing Level; SVVmed: average value of Subjective Visual Vertical in the group

Patients with probable MD: SN was observed in all subjects. SN rapid phase was directed towards the hearing loss side (irritative SN) in 3 cases (33\%), and towards the healthy side (deficitary SN) in 6 (67\%). A pathological deviation of the SVV was noticed in 7 patients (78\%). In $3 / 7$ subjects (43\%), we observed a deviation towards the hearing impairment side (otolithic deficitary phase), while in $4 / 7$ cases (57\%), the deviation was contralateral to the pathological side (otolithic irritative phase). The comparison between SN and SVV direction allowed us to define two semeiological patterns: «maculo-canal correspondence» and «maculo-canal dissociation", when canal and utricular signs showed the same or the opposite functional status respectively. A «maculo-canal correspondence» was noticed in 3/7 patients (43\%): 1 irritative and 2 deficitary. A "maculo-canal dissociation" was found in $4 / 7$ patients (57\%). Within "maculo-canal dissociation", the following combination of functional stages was noticed: 1 patient showed an irritative canal phase as opposed to an otolithic deficitary phase, while 3 patients displayed a canal deficitary phase compared to an irritative otolithic phase. In the remaining 2 patients, no otolith involvement was documented.

Patients with definite MD: Seven out of twelve patients (58\%) had a pre-existing hearing loss. SN was observed in all patients: it was irritative in $4 / 12$ cases $(33 \%)$ and deficitary in $8 / 12$ (67\%). A SVV pathological deviation was noticed in $9 / 12$ patients $(75 \%)$. A deficitary deviation was documented in $8 / 9$ cases (89\%), while an irritative deviation in $1 / 9$ subjects (11\%). A comparison of the 2 phases showed a "maculocanal correspondence" in all 9 patients with altered SVV: 8 of deficitary type, and 1 irritative. The patients with preexisting sensorineural hearing loss on the affected ear showed a deficitary type "macular-canal correspondence". Finally, the 3 patients with normal SVV showed an associated irritative SN.

day follow-up control: Data obtained on this control and statistical analysis is reported in (Table 2).

a) Patients with probable MD: No patient showed either SN or SVV persistent alteration/impairment on bithermal stimulation.

b) Patients with definite MD: No patient showed SN. SVV pathological deviation towards the affected side was noticed in $5 / 12$ patients $(42 \%)$. In these patients, a canal deficit on thermal stimulation and an ipsilateral hearing loss coexisted. Persistence of SVV deviation on 1-week control was more common in the definite MD group than in the probable MD one $\left(\mathrm{p}_{\mathrm{F}}<0.05\right)$.

\section{Discussion}

The results of this study allowed us to make a detailed comparison of the different pathophysiological and clinical features of otolithic involvement during the main peripheral vestibular diseases. The most important quantitative alterations of SVV were recorded in AUVL. SVV deviation was constantly ipsilateral to the affected side, consistent with the unilateral deficitary functional state. These findings are consistent with those reported in the literature $[8,9]$. The evolution of otolithic deficit can be well documented by SVV, which shows a gradual improvement (in terms of deviation degrees) and a final normalization in more than half of the cases.

In case of unilateral vestibular loss (but not in normal conditions), proprioceptive afferences to the central nervous system can influence the verticality perception error due to functional asimmetry. In this sense, the use of a podalic release test with the interposition of a soft support under the patient's feet can highlight the weight of plantar proprioceptive information on the SVV perceptual error induced by an unilateral sudden vestibular loss [10]. In particular, those patients who have a significant worsening effect on their SVV values at the provocative test (those of the group A) showed a greater ability to use (in basal condition) proprioceptive information to attenuate the verticality perception error. Besides, proprioception had a negative (group B) or a neutral effect (group C) on SVV perception in the other subjects.

This study shows that those patients with an initial compensatory effect of proprioception on verticality perception are more likely to recover a normal SVV and in a shorter time that other subjects. On the other side, an altered plantar proprioception negatively affects the retrieval of a normal SVV even after a long time.

Previous studies on SVV in BPPV patients have shown controversial results. Böhmer and Rickenmann, and Von Brevern et al. [10] did not observe SVV significant impairment $[4,11]$. Whereas Gall et al. [13] found an altered SVV [12]. Vannucchi 
reported higher SVV values among patients with persistent dizziness with respect to those in whom the resolution of BPPV was not accompanied by any residual symptom.

Our results in the BPPV group showed SVV deviation values lower than in the AUVL group, but higher than those recorded in the control group. Moreover, the side of the deviation was always the same of the affected canal. The reason for that is likely due to an otoconial depletion zone in the utricular macula caused by BPPV [14]. The lower weight of the macula could generate a tonic discharge of low intensity with the consequent functional asymmetry expressed by an ipsilateral deficitary SVV deviation [15]. Another interesting aspect is represented by SVV modification after efficacious canalolithiasis repositioning maneuvers. This SVV perception change might be a proof of utricular re-entry of otoconial debris and then of their originally utricular provenance. This observation on utricular origin of debris in BPPV was also reported by a previous study conducted with oVemps [16].

The mechanisms that may be involved are mechanical loading effects on the macula, potentially causing irritative effects on the receptor responsible for significant changes in SVV expressed as a correction in perceptual error, or even a reversal. The phenomenon, however, is short-lasting and seems to predict BPPV immediate resolution as a result of repositioning maneuvers $[14,15]$. The most variable behavior in SVV perception has been recorded in patients with MD. In this group, in fact, SVV measurement showed different results according to the time between observation and acute attack onset or MD beginning. More in detail, during MD acute attack, SVV perception, unlike AUVL, could be normal, diverted toward the healthy ear side or toward the affected side. Furthermore, the duration of the perceptual error in SVV seems to be more rapidly reversible than in AUVL, as shown by the results at 1 week follow-up after the acute attack.

This confirms the different genesis of the SVV change, which is a permanent utricular deficit in AUVL, while a temporary dysfunction in MD attack, except for MD advanced phases when a stable utricular hypofunction could be found. Previously, only Kumagami et al. [17] had studied utricular involvement through the analysis of SVV during MD attack. All their patients had, when present, a SVV deviation towards the affected side. These data are quite similar to those obtained in our group of definite MD patients, in which a deficitary SVV deviation was observed in association with a deficitary $\mathrm{SN}$, configuring a "maculocanal correspondence" in all cases. In this group of patients, a persistent deficitary deviated SVV was observed in association with signs of lateral canal hypofunction such as an impaired vestibular caloric response on the affected side.

Some new observations derived from the data obtained in our probable MD group of patients, in which a trend $\left(\mathrm{p}_{\mathrm{F}}=0.11\right)$ in showing an irritative deviation toward the healthy side during the acute attack was recorded. This would be consistent with the observation of increased amplitudes in bone-conducted Ocular VEMPs, especially in MD early stages [18]. Moreover, in this group, when comparing SVV with $\mathrm{SN}$, an opposite functional status (configuring the so-called "maculo-canal dissociation") was significantly more frequent than the definite MD group. These findings would reflect both the pathogenesis and the progression of MD [19]. More in detail, the increase in the endolymphatic hydrostatic pressure would not begin in a synchronous manner in all vestibular compartments because of the different caliber of membranous components. For this reason, canal and macular signs may be completely unrelated in type and time when analyzing the global vestibular functional status.

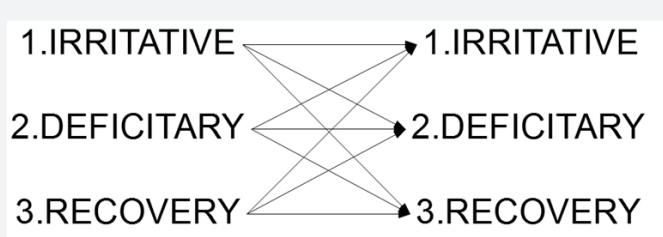

\section{CANAL PHASE OTOLITHIC PHASE}

Figure 3: Possible combination of phases at the moment of clinical observation of Ménière's disease attack.

Assuming that the onset and duration of canal and otolith signs are different, the observed clinical presentation will depend on the combination of canal and macular involvement (Figure 3). If the combination of signs (1-1), (1-3), (2-2), (31) and (3-3) occurs at the moment of observation, a "maculocanal correspondence" will be obtained; on the contrary, if the combination of sign (1-2), (2-1), (2-3) and (3-2) occurs, a "maculo-canal dissociation" will be found. The probability to observe each combination is not the same; it depends on the duration of receptor activation and its residual function, which is closely related to MD stage. For this reason, we believe, in agreement with electrophysiological studies, $[18,20]$ that the evolution of the disease and the gradual establishment of receptor hypofunction make the events more and more stereotyped, with a consequent increase in the frequency of deficitary "macularcanal correspondence".

Finally, when observing a patient in whom SN rapid phase and SVV deviation have the same direction, a differential diagnosis should be carried out between a lesion of the central vestibular ways across the brainstem midline and MD acute attack. If no other signs of CNS involvement are found, neuroimaging exams are negative and other common MD clinical features are noticed, the observation of a maculo-canal dissociation should suggest a new diagnosis of MD.

\section{Conclusion}

SVV in AUVL is useful to assess otholitic involvement during the acute attack and to monitor compensation during the follow-up. The importance of proprioception to attain a faster normalization SVV perception could have a role in vestibular 
rehabilitation therapy. SVV in BPPV confirms the utricular origin of otoconia; SVV normalization after repositioning maneuvers can confirm the efficacy of liberatory maneuvers. SVV in MD confirms the initially reversible otholitic involvement in such disease. The assessment of SVV, in association with SN, can give some information about the stage of the disease. Further studies are needed for a better understanding of the possible role of SVV testing in routine diagnostic practice and to improve our knowledge on the pathophysiological basis of our findings.

\section{References}

1. Halmagyi GM, Curthoys IS (1999) Clinical testing of otolith function. Ann NY Acad Sci 871(28): 195-204.

2. Halmagyi GM, Gresty MA, Gibson WP (1979) Ocular tilt reaction with peripheral vestibular lesion. Ann Neurol 6(1): 80-83.

3. Diamond SG, Markham CH (1983) Ocular counter rolling as an indicator of vestibular otolith function. Neurology 33(11): 1460-1469.

4. Böhmer A, Rickenmann J (1995) The subjective visual vertical as a clinical parameter of vestibular function in peripheral vestibular diseases. J Vestib Res 5(1): 35-45.

5. Brandt Th, Dieterich M, Danek A (1994) Vestibular cortex lesion affect the perception of verticality. Ann Neurol 35: 403-412.

6. Friedman G (1970) The judgement of the visual vertical and horizontal with peripheral and central vestibular lesion. Brain 93: 313-329.

7. (1995) Committee on Hearing and Equilibrium guidelines for the diagnosis and evaluation of therapy in Menière's disease. American Academy of Otolaryngology-Head and Neck Foundation, Inc. Otolaryngol Head Neck Surg 113(3): 181-185.

8. Halmagyi GM, Colebatch JG, Curthoys IS (1994) New tests of vestibular function. Baillieres Clin Neurol 3(3): 485-500.

9. Wade SW, Curthoys IS (1997) The effect of ocular torsional position on perception of the roll-tilt of visual stimuli. Vision Res 37(8): 10711078.

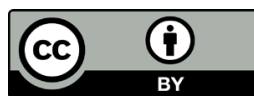

This work is licensed under Creative

Commons Attribution 4.0 License

DOI: $10.19080 /$ GJO.2017.07.555708
10. Faralli M, Longari F, Ricci G, Ibba MC, Frenguelli A (2009) Influence of extero- and proprioceptive afferents of the plantar surface in determining subjective visual vertical in patients with unilateral vestibular dysfunction. Acta Otorhinolaryngol Ital 29(5): 245-250.

11. von Brevern M, Schmidt T, Schönfeld U, Lempert T, Clarke AH (2006) Utricular dysfunction in patients with benign paroxysmal positional vertigo. Otol Neurotol 27(1): 92-96.

12. Gall RM, Ireland DJ, Robertson DD (1999) Subjective visual vertical in patients with benign paroxysmal positional vertigo. J Otolaryngol 28(3): 162-165

13. Vannucchi P (2003) La verticale e/o orizzontale visiva soggettiva. Acta Otorhinolaryngol Ital Suppl. 75: 74-79.

14. Faralli M, Manzari L, Panichi R, Botti F, Ricci G, et al. (2011) Subjective visual vertical before and after treatment of a BPPV episode. Auris Nasus Larynx 38(3): 307-311.

15. Faralli M, Ricci G, Ibba MC, Crognoletti M, Longari F, et al. (2009) Dizziness in patients with recent episodes of benign paroxysmal positional vertigo: real otolithic dysfunction or mental stress? J Otolaryngol Head Neck Surg 38(3): 375-380.

16. Bremova T, Bayer O, Agrawal Y, Kremmyda O, Brandt T, et al. (2013) Ocular VEMPs indicate repositioning of otoconia to the utricle after successful liberatory maneuvers in benign paroxysmal positioning vertigo. Acta Otolaryngol 133(12): 1297-1303.

17. Kumagami H, Sainoo Y, Fujiyama D, Baba A, Oku R, et al. (2009) Subjective visual vertical in acute attacks of Ménière's disease. Otol Neurotol 30(2): 206-209.

18. Manzari L, Tedesco AR, Burgess AM, Curthoys IS (2010) Ocular and cervical vestibular-evoked myogenic potentials to bone conducted vibration in Ménière's disease during quiescence vs during acute attacks. Clin Neurophysiol 121(7): 1092-1101.

19. Faralli M, Lapenna R, Mandalà M, Trabalzini F, Ricci G (2014) The first attack of Ménière's Disease: a study through SVV perception. Clinical and pathogenetic implications. J Vestib Res 24(5): 335-342.

20. Taylor RL, Wijewardene AA, Gibson WP, Black DA, Halmagyi GM, et al. (2011) The vestibular evoked-potential profile of Ménière's disease. Clin Neurophysiol 122(6): 1256-1263.

\section{Your next submission with Juniper Publishers will reach you the below assets}

- Quality Editorial service

- Swift Peer Review

- Reprints availability

- E-prints Service

- Manuscript Podcast for convenient understanding

- Global attainment for your research

- Manuscript accessibility in different formats

( Pdf, E-pub, Full Text, Audio)

- Unceasing customer service

Track the below URL for one-step submission https://juniperpublishers.com/online-submission.php 